\title{
Personality Traits and Subjective Health Complaints in Female TMD Patients and Healthy Controls
}

\author{
Christine Mohn*,1,2, Olav Vassend ${ }^{1}$, Berit Schie Krogstad ${ }^{3}$ and Stein Knardahl ${ }^{1,4}$ \\ ${ }^{I}$ Department of Psychology, University of Oslo, Norway \\ ${ }^{2}$ Vestre Viken Hospital Trust, Norway \\ ${ }^{3}$ Department of Prosthetic Dentistry and Oral Function, University of Oslo, Norway \\ ${ }^{4}$ Department of Work-Related Musculoskeletal Disorders, National Institute of Occupational Health, Oslo, Norway
}

\begin{abstract}
Background: Personality traits and general health complaints may influence the course of and treatment of chronic pain. However, only few studies compare more than one or two personality characteristics in chronic pain patients and healthy controls. This study compares the comprehensive non-pathological personality structure of female patients with temporomandibular disorders (TMD) and pain-free controls. Moreover, this study controls for the influence of Neuroticism, self-presentation bias, and acute pain sensitivity on the subjective report of general health complaints.

Methods: Twenty-five TMD patients were compared to 25 matched controls on personality traits (NEO Personality Inventory-Revised; NEO-PI-R), self-presentation bias (Social Desirability Scale; SDS), psychological distress (Symptom Checklist 90-Revised; SCL-90-R), and general somatic complaints. Experimental pain sensitivity was assessed by electrocutaneous and pressure pain stimulation.

Results: Compared to the controls, Extraversion and Openness were lower in the TMD group, and the TMD patients exhibited higher levels of psychological and musculoskeletal complaints also when Neuroticism, self-presentation bias, and acute pain sensitivity were held constant.

Conclusions: Low levels of Extraversion and Openness may dispose TMD patients to isolation and negative thought patterns. The elevated levels of psychological distress and general musculoskeletal pain in the TMD group add to previous reports of TMD as a complex condition also involving structures and processes outside of the orofacial region.
\end{abstract}

Keywords: Health complaints, NEO-PI-R, pain sensitivity, personality traits, TMD.

\section{INTRODUCTION}

Temporomandibular disorders (TMD) comprise a category of complaints of pain and/or mobility dysfunction of the masticatory structures [1]. TMD are assumed to involve changes in endogenous regulatory pain pathways, resulting in maladaptive emotional, physiological and neuroendocrine responses to physical and psychological stressors $[2,3]$.

The influence of psychological problems and distress in the development and maintenance of several chronic pain conditions is well known [4]. Personality traits, i.e., nonpathological, stable psychological characteristics, may also affect chronic pain conditions [5]. For example, personality traits may influence fear and catastrophizing, which may increase the threat value of pain and in turn amplify pain signals and psychological distress [6, 7]. Moreover, personality traits may determine choices of coping strategies [8] that in turn may affect long-term outcomes and disability [5].

*Address correspondence to this author at the Department of Psychology, $\mathrm{P}$ O Box 1094 Blindern, 0317 Oslo, Norway; Tel.: +47 228451 15; Fax: +47 228450 01; E-mail: christinemohn@ @otmail.com
There is evidence of personality traits, most notably Neuroticism $(\mathrm{N})$, influencing suffering and coping in established chronic pain $[5,9]$. $\mathrm{N}$ denotes a tendency to experience anxiety, depression, and irritability, although this trait also consists of aspects not necessarily affiliated with the concept of distress, e.g., impulsivity and self-awareness [8].

There is little research on the relationship between personality traits and TMD. Some of the studies in this field have employed the Minnesota Multiphasic Personality Inventory (MMPI) [10, 11], an inventory that primarily is designed to diagnose personality disturbances $[8,12]$. Although one may argue that the distinction between high levels of $\mathrm{N}$ and pathological distress may be blurred, in one of the very few studies that have assessed non-pathological personality traits, Southwell et al. [13] found that TMD patients scored significantly higher on $\mathrm{N}$ and lower on Extraversion (E) than did the healthy controls. A weakness of that study, as well as of other studies of personality traits in other chronic pain groups $[14,15]$, is that assessment is limited to only one or two personality traits.

In healthy individuals, several other personality traits seem relevant for health behaviours that may influence both the susceptibility to acute illnesses and the maintenance of 
chronic disorders. High levels of Agreeableness (A) and Conscientiousness (C) are related to consumption of healthy food and tobacco avoidance [16, 17]. In addition, Openness (O) may predict the willingness to take part in risky behaviours, e.g., drug use [16].

The traits N, E, O, A, and C constitute the Five-Factor Model (FFM) of personality [8]. A study of how a number of circumscribed traits (e.g., Optimism and Locus of Control) often assessed in health-related research but unrelated to larger theoretical frameworks of personality may converge with the broader domains of the FFM, provides evidence that many of the isolated constructs may tap the traits of the FFM [18]. Hence, the employment of the FFM as a unifying frame of reference in order to arrive at a fuller picture of a pain patient's psychological make-up and coping resources seems justified. To our knowledge, comprehensive assessments of personality traits have not been obtained in TMD patients, despite the relevance of personality traits for coping and adherence to treatment regimes in chronic pain patients [5, 9].

Elevated levels of psychological distress, e.g., anxiety and depression, are common in TMD groups $[19,20]$. The presence of psychological distress, i.e., depression, anxiety, and somatization $[21,22]$ has been related to persistent or recurrent symptoms and lack of treatment effects in established TMD. Moreover, psychological distress and poor coping styles may predict the transition from acute to chronic TMD [23]. On the other hand, early intervention with biofeedback training and cognitive-behavioural counseling of acute TMD patients with elevated levels of emotional distress seems to reduce pain levels and psychological symptoms as well as improving coping strategies [24].

Many orofacial pain patients report pain from anatomical sites other than the orofacial region as well as symptoms like fatigue and dizziness $[25,26]$. Such complaints may reduce the likelihood of a favourable treatment outcome for TMD [27]. A recent longitudinal study revealed that while $30 \%$ of all TMD patients were in remission five years after receiving treatment at a TMD clinic, the patients presenting with widespread musculoskeletal pain at baseline (36\%), were recurrent cases with no significant reduction of TMD symptoms [22]. Another longitudinal study demonstrated a remission rate of $46 \%$ after five years while high levels of anxiety, depression, and somatization at baseline predicted recurrence of TMD, regardless of large individual variations in baseline pain severity [21]. Hence, screening for pain outside of the orofacial region as well as psychological distress clearly seems valuable with respect to the estimation of illness progression and treatment effects.

Health complaint report may be influenced by personality traits [5]. Both $\mathrm{N}$ and a related concept, Negative Affectivity (NA), are associated with physical complaints and symptoms, although there is little evidence of objective signs of illness in individuals high in N or NA [5, 28, 29]. Moreover, studies of self-presentation bias, assessed by the Social Desirability Scale [30], indicate that in both pain-free individuals [31] and chronic pain groups [32] high levels of Social Desirability is associated with low levels of pain complaints. It is assumed that individuals displaying self-presentation bias may tend to suffer in silence as to appear stronger or more robust than others. Hence, the impact of $\mathrm{N}$ and Social
Desirability should be controlled for in studies of selfreported health complaints.

Moreover, one's present pain level is likely to affect retrospective symptom report, in that a high current pain level may generate an overestimation of previous or current complaints [33]. Moreover, information of general health variables is typically obtained in close proximity to acute pain stimulation in experimental studies, risking carry-over effects from experimental to clinical pain. To our knowledge, this possibility of confounding relationship has not previously been addressed in studies of subjective health complaints in chronic pain patients. Therefore, a statistical control for the possible influence of experimental pain sensitivity on subjective health complaints is included in this study.

The aim of the present study was to determine the personality structure and pattern of psychological and somatic health complaints in TMD, in order to further the understanding of factors that may contribute to the development, maintenance, and treatment of this disorder.

Specifically, the aims were to investigate whether: 1) the five personality traits of the FFM differ in TMD patients and controls, and 2) when controlling for Neuroticism, selfpresentation bias, and pain sensitivity, TMD patients differ from controls in terms of psychological and general somatic complaints.

\section{MATERIALS AND METHODOLOGY}

\section{Subjects}

The TMD patients were 28 females recruited from the outpatient clinic of the Dental Faculty, University of Oslo ( $n$ $=19$ ) and from one advertisement in an Oslo newspaper ( $\mathrm{n}=$ 9). All patients, including those who were recruited through the newspaper ad, underwent a structured clinical examination based on the Research Diagnostic Criteria for TMD (RDC-TMD) [1] by the Dental Faculty research physiotherapist, who was calibrated according to the RDC-TMD. Inclusion criteria were a diagnosis of TMD and age between 20 and 50. Exclusion criteria (self-reported) were other chronic illnesses than TMD (e.g., rheumatic, vascular, or psychiatric disorders), pregnancy, and inability to understand spoken and written Norwegian. Exclusion criteria (selfreported) specifically targeting other orofacial-related illnesses than TMD were rheumatoid arthritis, temporal arteritis, trigeminal neuralgia, parotitis, and sinusitis. The clinical examination and the responses to the questionnaires described below revealed no significant differences in years of TMD symptoms, duration of symptoms, personality traits, and general health complaints for between the two TMD samples (all $p \mathrm{~s}>.05$ ).

Fifty-seven healthy women were recruited among graduate students of and from the central administration of the University of Oslo, and among employers at an agency providing secretarial substitutes. Exclusion criteria (selfreported) were pregnancy, chronic physical and mental illnesses, daily use of medication apart from oral contraception, and inability to understand spoken and written Norwegian.

From these samples, 25 TMD patients were matched for age (+- 6 years), level of education, smoking, and exercise with 25 healthy controls (Table 1). Diagnostic findings 
Table 1. Demographic Characteristics of the Participants

\begin{tabular}{|c|c|c|}
\hline & TMD (n=25) & Controls $(n=25)$ \\
\hline Age & 35.2 (SD 11.9, range $20-55$ years) & $\begin{array}{c}33.9 \text { (SD 11.1, range } 20- \\
51 \text { ) years }\end{array}$ \\
\hline Body Mass Index & $23.1(\mathrm{SD} 3.8$, range $16.5-29.9)$ & $\begin{array}{c}21.8(\mathrm{SD} 2.9, \text { range } 18.2- \\
28.6)\end{array}$ \\
\hline Regular physical exercise & $68.0 \%$ & $80.0 \%$ \\
\hline College level education & $64.0 \%$ & $64.0 \%$ \\
\hline Grade school only & $16.0 \%$ & $12.0 \%$ \\
\hline Working full time (>37.5 hours/week) & $56.0 \%$ & $48.0 \%$ \\
\hline Working part time & $16.0 \%$ & $12.0 \%$ \\
\hline Currently studying & $20.0 \%$ & $44.0 \%$ \\
\hline Currently on sick leave & $9.0 \%$ & None \\
\hline Disabled & None & None \\
\hline Married / cohabiting & $48.0 \%$ & $44.0 \%$ \\
\hline Divorced & $12.0 \%$ & $12.0 \%$ \\
\hline Years of TMD diagnosis & 8.35 (SD 7.3, range 2-30) years & - \\
\hline \multicolumn{3}{|l|}{ Subgroup of TMD: } \\
\hline Arthralgia, arthrosis & $13.0 \%$ & - \\
\hline Myalgia & $52.2 \%$ & - \\
\hline Arthralgia + myalgia & $34.8 \%$ & - \\
\hline Disc displacement & None & - \\
\hline Unassisted opening (mm) & 43.6 (SD 7.9, range 29-65) & - \\
\hline Number of painful craniofacial muscle sites & 10.5 (SD 4.3, range $2-18)$ & - \\
\hline \multicolumn{3}{|l|}{ Subjective complaints of TMD symptoms: } \\
\hline Insignificantly troubled & $4.8 \%$ & - \\
\hline Slightly troubled & None & - \\
\hline Moderately troubled & $33.3 \%$ & - \\
\hline Significantly troubled & $42.9 \%$ & - \\
\hline Seriously troubled & $19.0 \%$ & - \\
\hline Oral splints / implants & $15.0 \%$ & - \\
\hline
\end{tabular}

Age, Body Mass Index, Years of TMD diagnosis, Unassisted opening, and Number of painful craniofacial muscle sites in mean. N=50.

according to the RDC-TMD [1], e.g., diagnostic subgroups, number of craniofacial muscles painful to palpation, are listed in Table $\mathbf{1 .}$

The subjects were required to refrain from vigorous physical activity, drinking tea or coffee, smoking, and having large meals during the last 4 hours before the experiment. Alcohol was not allowed the last 12 hours before the experiment. All subjects received written information of the study, all signed an informed consent before the experiment, and were informed that they were free to withdraw any time. The study was conducted according to the Helsinki Declaration, and approved by the regional Medical Ethics Committee. All the subjects received NOK 500 (approximately USD 75, April 2007) for their participation.

\section{Instruments and Laboratory}

The present study was part of a larger project on psychological and physiological factors in TMD, which 
included a psychophysiological experiment [34]. All the subjects first went through the psychophysiological experiment where mean arterial pressure, heart rate, skin blood flux, and electromyography were recorded while the subjects performed various cognitive tasks, lasting 2.5 hours. These data fall outside of the aim and scope of the present paper and will not be reported here.

At the beginning of the experiment, two assessments of electrocutaneous and pressure pain sensitivity were made. These two assessments were averaged and subjected to analyses for the present study. Briefly, the back of the participants' left hand was given electrocutaneous stimulation, and pressure algometry was performed on the right $\mathrm{m}$. masseter and the sternum. The participants were asked to report the sensory threshold (when they first noticed the stimulation), the pain threshold (when the stimulation felt painful), and to press a hand-held button when they reached their level of tolerance (when they did stand further increases in stimulation). For detailed information on the pain testing procedure, see Mohn et al. [35].

\section{SELF-REPORT INSTRUMENTS}

After the experiment, all the subjects filled in questionnaires as described below.

The NEO Personality Inventory - Revised (NEO-PI-R) $[8,36]$ consisting of 240 items, assesses five broad personality domains or factors. Each of the five traits consists of six subscales, or facets (Table 2).

The Social Desirability scale (SDS) [30, 37], consisting of 33 items, assesses self-presentation bias.

The Symptom Checklist 90-R (SCL-90-R) [38, 39] assesses emotional distress symptoms during the week preceding the investigation. The global score (Global Severity Index, GSI), based on 90 items, is the subject's mean score of the instrument.

The Health Complaint Report (HCR), designed at the Norwegian National Institute of Occupational Health for use in working populations, assesses general health complaints [40]. It measures intensity and duration of musculoskeletal pain (12 items), gastrointestinal symptoms (6 items), psychological distress (5 items), allergy (3 items), and upper airway infection (2 items) during the past 14 days. For intensity of symptoms, responses are made on a four-point Likert scale ranging from "not troubled at all" to "very troubled". For duration of symptoms, responses are made on a three-point Likert scale ranging from "1-5 days" to 11-14 days". A complaint-severity score for each of the health complaints was computed by multiplying the intensity score by the duration score. Moreover, indices based on the mean severity scores multiplied with the mean duration scores of the musculoskeletal symptoms (MSI), gastrointestinal symptoms (GI), allergic complaints (AI), and upper airway infection complaints (UAII) were computed (score range 09).

\section{STATISTICS}

The statistical procedures were performed using SPSS, release 16 (SPSS Inc., Chicago, IL, USA). Preliminary analyses of the sample distributions included determination of kurtosis, skewness, and outliers. For some of the vari- ables, 1-3 outliers (i.e., individuals scoring 3 SD above or below the mean score) were identified. Scatter plots were visually inspected in order to detect bivariate outliers. If present, the outliers were excluded from the analyses. The number of subjects included is specified in each table of results.

Group differences were analyzed by way of independent samples t-tests. Cohen's d's were calculated to describe effect sizes.

If there were significant group differences in personality traits, group differences in the facets of the relevant traits were analyzed with t-tests in order to obtain more detailed information on the personality differences.

Statistical control of the effect of $\mathrm{N}$ and Social Desirability on the report of general health complaints was done by a series of regression analyses run with a psychological or somatic health complaint as the dependent variable, diagnosis as the study variable, and $\mathrm{N}$ and Social Desirability as control variables.

Statistical control of the effect of pain sensitivity on the report of general health complaints was done by a series of regression analyses run with a psychological or somatic health complaint as the dependent variable, diagnosis as the study variable, and experimental pain sensitivity as the control variable.

In order to study the relationship between $\mathrm{N}$ and severity of TMD pain, duration of TMD symptoms, and number of painful craniofacial muscle sites (Table 1) in the TMD group, Pearson's correlation analyses were performed.

The significance level was set at .05 for this hypothesisgenerating study.

\section{RESULTS}

\section{Personality Traits and TMD}

The mean scores of the five traits of the NEO-PI-R of the control group were on the middle level, according to the Norwegian norms of this inventory [36]. The TMD patients reported significantly lower levels of $\mathrm{E}$ and $\mathrm{O}$ compared to the control group (Table 2). These two scores were on the low level, according to the Norwegian norms. Relative to the control group, at the facet level of these traits, the TMD group exhibited significantly lower levels of four of the facets of $E$ and three of the facets of $O$ (Table 2).

\section{Pain Sensitivity in TMD}

There were no statistically significant group differences in experimental pain sensitivity. These results are discussed elsewhere [35].

\section{Subjective Health Complaints and TMD}

The mean scores of the SCL-90-R of the control group were comparable to the

Norwegian norms [39]. Most of the psychological complaints (Table 3) were elevated in the TMD group. Three scales (Somatization, Obsession-Compulsivity, and Depression) were elevated above 1 , which is characteristic of psychiatric patients [38]. Moreover, the musculoskeletal pain complaint index was higher in the TMD group as contrasted with the control group (Table 4). This was primarily due to 
Table 2. Personality Traits (NEO-PI-R and Social Desirability Scale) in TMD Patients and Healthy Controls

\begin{tabular}{|c|c|c|c|c|}
\hline Personality trait & Mean (SD) & Mean (SD) & & \\
\hline Extraversion & $104.4(19.7)$ & $119.9(16.5)$ & $3.02 * *$ & -1.11 \\
\hline E-Gregariousness & $18.9(6.5)$ & $23.0(4.6)$ & $2.55 *$ & \\
\hline E-Activity & $16.9(4.2)$ & $19.8(3.6)$ & $2.64 *$ & \\
\hline E-Positive emotions & $19.4(5.0)$ & $22.8(5.6)$ & $2.30 *$ & \\
\hline Openness & $109.4(16.0)$ & $123.2(14.8)$ & $3.16 * *$ & -0.90 \\
\hline O-Values & $20.6(3.9)$ & $22.9(3.4)$ & $2.21 *$ & \\
\hline Agreeableness & $121.4(14.0)$ & $126.2(15.9)$ & $1.14 \mathrm{~ns}$ & -0.32 \\
\hline Conscientiousness & $111.4(16.1)$ & $111.1(21.6)$ & $-0.10 \mathrm{~ns}$ & 0.02 \\
\hline Social Desirability & $23.4(2.6)$ & $24.2(3.4)$ & $0.87 \mathrm{~ns}$ & -0.26 \\
\hline
\end{tabular}

$\mathrm{T}=$ significance test of group differences. $* * \mathrm{p}<.01, * \mathrm{p}<.05, \mathrm{~ns}=$ non significant (2-tailed). $\mathrm{d}=$ Cohen's d, effect size assessment of group differences. $\mathrm{N}=50$.

the group differences in headache, neck pain, shoulder pain, upper and lower back pain, and leg pain.

Although there was no statistically significant group difference in $\mathrm{N}$, this personality trait was entered in the regression analyses due to the moderate effect size of this difference $(d=.51)$. The regression analyses described in the Statistics section generated essentially the same results as depicted in Tables 3 and 4: When $\mathrm{N}$ and Social Desirability were controlled for, diagnosis was confirmed as the main predictor variable for Somatization, Obsession, Depression, Anxiety, Hostility, and the GSI (Fs for the total model > $2.99, \mathrm{p}<.05, \beta \mathrm{s}$ for diagnostic group $>.38$, Ts for diagnostic group $>2.40, \mathrm{p}<.05)$. When experimental pain sensitivity was controlled for, diagnosis was confirmed as the main predictor variable for Somatization, Obsession, Depression, Anxiety, Hostility, and the GSI (Fs for the total model > $3.65, \mathrm{p}<.05, \beta \mathrm{s}$ for diagnostic group $>.29$, Ts for diagnostic group $>2.09, \mathrm{p}<.05)$.

When $\mathrm{N}$ and Social Desirability were controlled for, diagnosis was confirmed as the main predictor variable for MSI ( $\mathrm{F}$ for the total model $=8.44, \mathrm{p}<.001, \beta$ for diagnostic group $=.62, \mathrm{~T}$ for diagnostic group $=4.62, \mathrm{p}<.001)$ and AI ( $\mathrm{F}$ for the total model $=2.87, \mathrm{p}<.05, \beta$ for diagnostic group $=.42, \mathrm{~T}$ for diagnostic group $=2.83, \mathrm{p}<.01$ ). When experimental pain sensitivity was controlled for, diagnosis was confirmed as the main predictor variable for MSI and AI (Fs for the total model $>4.20, \mathrm{p}<.05, \beta$ s for diagnostic group $>$ .35 , Ts for diagnostic group $>2.61, \mathrm{p}<.05$ ).

The correlation analyses of $\mathrm{N}$ and clinical characteristics of TMD described in the Statistics section generated no statistically significant associations (data not shown).

\section{DISCUSSION}

To our knowledge, this study is the first to provide a comprehensive personality assessment of TMD patients and statistical control for the effect of Neuroticism (N), selfpresentation bias, and acute pain sensitivity on the reporting of general health complaints.

The current TMD patients exhibited a lower level of Extraversion (E) and Openness (O). Previous studies of personality traits in chronic pain patients have mainly concentrated on $\mathrm{N}$ and ignored other traits [5], risking loss of information relevant for the understanding of the patients' adjustment to pain and therapy.

Nitch \& Boone [9] demonstrated that personality traits may influence coping with established chronic pain. Their findings suggest that lack of extraversion or sociability (low E) may increase the risk of loneliness and isolation. $\mathrm{E}$ is not assumed to be as strongly related to suffering as $\mathrm{N}$ is, although the protective role of $\mathrm{E}$ has been acknowledged; high levels of E, i.e., increased sociability, may take on a protective role for at least two reasons: socially active individuals are provided with frequent distractions from pain, and the social support these people receive may decrease painrelated stress levels [41]. In addition, experimental pain sensitivity data suggest that high $\mathrm{E}$ is associated with pain expression and the communication of discomfort [41]. The clinical implication is that high $\mathrm{E}$ individuals may receive treatment relatively fast due to their rapid communication of pain, as well as having ample opportunities for social and emotional support. The results of the analyses of group differences in facets of $E$ show that E-Warmth, EGregariousness, E-Activity, and E- Positive emotions were 
Table 3. Psychological Health Complaints (SCL-90-R) in TMD Patients and Healthy Controls

\begin{tabular}{|c|c|c|c|c|}
\hline & TMD & Controls & T \\
\hline \hline Complaint & Mean (SD) & Mean (SD) & $-6.10 * * *$ & 1.75 \\
\hline Somatization & $1.4(0.7)$ & $0.4(0.4)$ & $-3.28 * *$ & 0.99 \\
\hline Obsession-compulsivity & $1.3(0.8)$ & $0.6(0.6)$ & $-2.33 *$ & 0.67 \\
\hline Interpersonal sensitivity & $0.9(0.6)$ & $0.5(0.6)$ & $-3.55 * * *$ & 0.96 \\
\hline Depression & $1.2(0.9)$ & $0.5(0.5)$ & $-3.27 * *$ & $-2.72 *$ \\
\hline Anxiety & $0.7(0.5)$ & $0.3(0.4)$ & $-1.41 \mathrm{~ns}$ & 0.88 \\
\hline Angry hostility & $0.5(0.6)$ & $0.2(0.2)$ & $-0.87 \mathrm{~ns}$ & 0.33 \\
\hline Phobia & $0.2(0.3)$ & $0.1(0.3)$ & $0.02 \mathrm{~ns}$ & 0.44 \\
\hline Paranoid ideation & $0.6(0.4)$ & $0.4(0.5)$ & $-2.82 * *$ & 0.00 \\
\hline Psychoticism & $0.8(0.5)$ & $0.4(0.4)$ & 0.38 \\
\hline
\end{tabular}

$\mathrm{T}=$ significance test of group differences. ${ }^{* * *} \mathrm{p}<.001, * * \mathrm{p}<.01, * \mathrm{p}<.05, \mathrm{~ns}=$ non significant (2-tailed). $\mathrm{d}=$ Cohen's $\mathrm{d}$, effect size assessment of group differences. $\mathrm{N}=50$.

significantly lower in the TMD group. This points in the direction of TMD patients being at risk for loneliness and lack of social support.

Low levels of $\mathrm{O}$ may result in maladaptive coping patterns due to a relative lack of creativity [9]. Indeed, Miller [42] proposes that $\mathrm{O}$ is one of the most important factors regarding outcome of treatment for psychological disturbances due to low $\mathrm{O}$ being correlated with constricted affect and proneness to be stuck in negative patterns of thought. These suggestions seem to fit with our findings: Compared to the control group, the present TMD group scored significantly in O-Feelings, O-Ideas, and O-Values. Moreover, Phillips and Gatchel [41] speculate that low $\mathrm{O}$ in combination with low E may offer particular difficulties in terms of reduced ability to recognize and communicate emotions. However, it must be noted that none of the personality traits reached alarmingly low levels according to the Norwegian norms [36]. Therefore, we have no reason to assume that the present TMD group is characterized by abnormal personality traits.

Traditionally, personality traits have been assumed to influence the development and maintenance of pain [5]. However, the consequences of chronic pain or illness, e.g., physical limitations, economical difficulties, and social isolation, may generate considerable suffering and affect those aspects of personality that are most strongly related to psychological distress e.g., depressive tendencies, anxiety and worry, hostility, and introversion. Hence, it is not inconceivable that personality changes may occur due to enduring pain conditions, although personality traits as conceptualised by the FFM seem remarkably robust in the face of challenges to health and lifestyle [8].

In accordance with previous research, we observed higher levels of psychological distress [19, 20, 26, 27] and musculoskeletal pain $[25,26]$ in the TMD group relative to the control group. Importantly, these differences were main- tained after having statistically controlled for $\mathrm{N}$, selfpresentation bias, and pain sensitivity. We are aware of no other study with this type of control for these variables, which have been reported to influence symptom disclosure in healthy individuals $[5,28,29]$. Thus, the present study has placed previous findings of elevated scores of general health complaints in TMD patients on a more secure footing, indicating that personality traits and pain sensitivity do not seem to have a large influence on self-reported symptoms in this chronic pain group. However, the relatively low sample size did not allow for statistical control for other personality traits than N. Future studies should aim to explore the possible role for the other four FFM-traits in subjective symptom report.

The direction of causality between psychological distress and TMD is not determined. Symptoms of psychological disorders, most notably depression, may be a natural consequence of having a chronic pain condition, and there is evidence that a reduction of TMD symptoms is followed by reduced levels of emotional distress [22, 43]. On the other hand, depression has been identified as a predictor for first onset of TMD pain [44], chest pain, and headache [45]. Moreover, affective and nociceptive pathways coincide anatomically, and the neurotransmittors serotonin and norepinephrine are involved in nociception as well as depression and anxiety [46]. It has been suggested that at least in some groups of chronic pain patients a trait of susceptibility to both pain and psychological symptoms may exist [47], perhaps due to an imbalance of the neurotransmitters involved in both conditions [46].

The comorbidity of psychological distress and pain, in addition to the lack of organic abnormalities in many musculoskeletal pain disorders, have generated suggestions that chronic pain conditions may be masked psychiatric disorders, with patients reporting somatic complaints instead of psychological distress to avoid an assumed social stigma of mental instability. The TMD patients in the present study 
Table 4. Somatic Health Complaints (HCR) in TMD Patients and Healthy Controls

\begin{tabular}{|c|c|c|c|c|}
\hline Complaint & Mean (SD) & Mean (SD) & & \\
\hline Headache & $1.8(0.9)$ & $0.8(0.7)$ & $-4.23 * * *$ & 1.24 \\
\hline Pain in left shoulder & $0.9(1.2)$ & $0.2(0.4)$ & $-3.14 * *$ & 0.78 \\
\hline Pain in right shoulder & $0.9(1.1)$ & $0.3(0.4)$ & $-2.55 *$ & 0.72 \\
\hline Pain in left arm & $0.2(0.6)$ & $0.1(0.4)$ & $-1.00 \mathrm{~ns}$ & 0.20 \\
\hline Pain in right arm & $0.4(0.7)$ & $0.1(0.3)$ & $-2.15 *$ & 0.56 \\
\hline Pain in upper back & $1.2(1.0)$ & $0.2(0.4)$ & $-4.65 * * *$ & 1.31 \\
\hline Pain in lower back & $1.3(0.9)$ & $0.5(0.6)$ & $-3.36 * *$ & 1.05 \\
\hline Pain in chest & $0.3(0.4)$ & $0.0(0.0)$ & $-2.75 *$ & 1.06 \\
\hline Pain in legs & $0.8(0.9)$ & $0.1(0.3)$ & $-3.69 * * *$ & 1.04 \\
\hline Gastrointestinal Index (GI) & $0.1(0.1)$ & $0.1(0.1)$ & $-1.10 \mathrm{~ns}$ & 0.00 \\
\hline Allergy Index (AI) & $0.3(0.5)$ & $0.1(0.1)$ & $-2.08 \mathrm{~ns}$ & 0.55 \\
\hline Upper Airway Infection Index (UAII) & $0.1(0.1)$ & $0.1(0.1)$ & $0.20 \mathrm{~ns}$ & 0.00 \\
\hline
\end{tabular}

$\mathrm{T}=$ significance test of group differences. $* * * \mathrm{p}<.001, * * \mathrm{p}<.01, * \mathrm{p}<.05, \mathrm{~ns}=$ non significant $(2$-tailed). $\mathrm{d}=\mathrm{Cohen}$ 's $\mathrm{d}$, effect size assessment of group differences. $\mathrm{N}=48$-50.

reported elevated levels of somatic complaints, which may indicate the presence of somatization processes. Somatization processes denote the tendency to communicate emotional and social distress through physical symptoms [48]. Previous studies have found somatization processes to be predictive of chronic widespread pain [49] in addition to being predictive of poor treatment outcome in established TMD [21, 22]. On the other hand, somatization may occur secondary to chronic pain. As the pain problem progresses, an understandable response may be an increased focus on bodily processes and symptoms [5], even in individuals with low pre-pain levels of somatization or other psychological distress. Although no conclusions regarding causal direction can be made, it must be noted that there was a significant relationship between duration of TMD symptoms and somatization in the present study. The ultimate consequence may be a negative feedback-loop where chronic pain and negative affect interact in a circular manner.

Compared to the pain-free controls, the TMD patients of the present study reported significantly higher levels of headache and pain in the neck, back, and legs. There were, however, considerable inter-individual variations in the TMD group as evidenced by the large standard deviations of the analyses. Possibly, some groups of TMD patients are more troubled by generalised pain than the others.

The natural issue arising at this point is the relationship between TMD and fibromyalgia syndrome (FMS), a diag- nostic entity sharing some of the symptoms of TMD, e.g., widespread pain, fatigue, sleep disturbances, and psychological distress. One study has found that general musculoskeletal pain predates orofacial pain and concluded that TMD may simply be a characteristic of late-stage FMS [50]. Despite these similarities, there seems to be important differences between these illnesses, as Dao et al. [51] have found that a sizeable minority $(21 \%)$ of TMD patients had orofacial pain for up to 15 years without general body pain. Moreover, FMS seems to be characterized by more severe pain and higher levels of psychological distress [51, 52]. In addition, the prevalence of TMD does not seem to increase with age the way FMS does [51, 52]. Possibly, TMD and FMS occupy different ends of a continuous spectrum of chronic musculoskeletal pain resulting from similar, as of yet unknown, pathogenic factors.

Likewise, the relationship of TMD to chronic tensiontype headache $(\mathrm{CTTH})$ is difficult to entangle. Based on the significant group differences in self-reported headache, at least some of our patients may have been candidates for the CTTH diagnosis. The causal direction between CTTH (i.e., idiopathic headache in more than 15 days pr. month for more than 3 months) [53] and orofacial pain has not been determined [54]. Moreover, both facial pain and headache may be symptoms of a common musculoskeletal pain disorder, e.g., FMS [55]. These relations await further elucidation. 
A limitation of the present study is the relatively low number of subjects. As the differences in personality traits and health complaints between the TMD group and the control group were significant, the sample sizes did not seem relevant for these comparisons. However, the sample sizes did not permit the statistical division of the TMD patients into sub-groups regarding a primary myalgic or a primary arthralgic origin of their symptoms. Research on psychological differences between subgroups of TMD patients has generated equivocal results. Some studies have found that the myalgic subgroup tend to report higher levels of psychological and somatic distress than the other subgroups, also when controlling for differences in pain level $[20,56]$. However, others [57] have not observed such differences. Moreover, it generally seems difficult to allocate TMD patients into only one subgroup, as a combination of myalgic and arthralgic symptoms seems to be the norm for most of these patients $[22,58]$.

Relatedly, the present study did not include TMD patients with disc displacement. This condition is characterized by the disc of the temporomandibular joint being displaced from its position between the condyle and the eminence [1]. This subgroup consitute a substantial proportion of TMD patient populations [59], and the present findings may not generalize to this subgroup.

Second, the present TMD sample was drawn from both a tertiary clinic and the population. Psychological differences between clinical and community samples of chronic pain patients have been described, in that clinical samples may report higher levels of pain severity and suffering [21]. However, there were no significant group differences between the clinical and the population samples. Importantly, there were no differences in years of suffering from TMD or subjective level of suffering. Possibly, we recruited a relatively severely troubled community sample, and our pooling of the two samples into one TMD group seems justified. However, the population sample was small $(\mathrm{n}=9)$, and it is not inconceivable that larger samples would generate significant group differences.

Third, the participants in the present study were all female. TMD not only seems to be more prevalent in women [60], it has also been reported that female TMD sufferers report more psychological distress and physical symptoms compared to male TMD patients [61]. The current results may not generalize to the male TMD population.

Fourth, the participants in the control group did not undergo a clinical examination to ascertain their status as free of TMD symptoms. Pain from and reduced mobility of the jaw region often occur in the general population [1], and it is possible that some of the members of the control group may have experienced such symptoms without fulfilling all the criteria for a TMD diagnosis. In such cases, the healthy, pain-free status of the individuals could be questioned. It is a limitation of the present study that the selection of participants for the control group relied on a self-reported lack of illness.

\section{CONCLUSION}

Low levels of Extraversion and Openness may dispose TMD patients to isolation and negative thought patterns. The elevated levels of psychological distress and general muscu- loskeletal pain in the TMD group adds to previous reports of TMD as a complex condition also involving structures and processes outside of the orofacial region. The report of general health complaints in the TMD group was not influenced by Neuroticism, self-presentation bias, or experimental pain sensitivity. Future studies should aim to determine the role of personality traits for treatment outcome in TMD and clarify the causal relationship between TMD and other chronic musculoskeletal pain disorders such as tension-type headache and FMS.

\section{ACKNOWLEDGEMENTS}

Ms Cathrine Bjordal Bergheim, Ms Eva Helene Mjelde, Ms Merete Nyrerød, and Ms Janne Schiøll assisted during the data collection phase of this study. Computer programming was done by Mr Øystein Klingenberg, Mr Dag Erik Eilertsen and Dr Dagfinn Matre. Dr Tore C Stiles is acknowledged for his comments to an earlier version of this manuscript. This study was supported by grant $112672 / 330$ from the Norwegian Research Council.

\section{REFERENCES}

[1] Dworkin SF, LeResche L. Research diagnostic criteria for temporomandibular disorders. J Craniomandib Dis Facial Oral Pain 1992; 6: 301-55.

[2] Fillingim RB, Maixner W, Kincaid S, Sigurdsson A, Harris MB. Pain sensitivity in patients with temporomandibular disorders: relationship to clinical and psychosocial factors. Clin J Pain 1996; 12: 260-9.

[3] Maixner W, Fillingim R, Booker D, Sigurdsson A. Sensitivity of patients with painful temporomandibular disorders to experimentally evoked pain. Pain 1995; 63: 341-51.

[4] Gatchel RJ, Turk DC, Eds. Psychosocial factors in pain. New York: Guilford Press 1999.

[5] Gatchel RJ, Weisberg JN, Eds. Personality characteristics of patients with pain. Washington DC: American Psychological Association 2000.

[6] Hassett AL, Cone JD, Patella SJ, Sigal LH. The role of catastrophizing in the pain and depression of women with fibromyalgia syndrome. Arhtritis Rheum 2000; 43: 2493-500.

[7] Turner JA, Dworkin SF, Mancl L, Huggins KH, Truelove EL. The roles of beliefs, catastrophizing, and coping in the functioning of patients with temporomandibular disorders. Pain 2001; 92: 41-51.

[8] Costa PT Jr, McCrae RR. NEO-PI-R, Professional Manual. Odessa, FL: Psychological Assessment Resources 1992.

[9] Nitch SR, Boone KB. Normal personality correlates of chronic pain subgroups. J Clin Psychol Med Sett 2004; 11: 203-09.

[10] Mongini F, Ciccone G, Ibertis F, Negro C. Personality characteristics and accompanying symptoms in temporomandibular joint dysfunction, headache, and facial pain. J Orofac Pain 2000; 14: 528.

[11] Parker MW, Holmes EK, Terezhalmy GT. Personality characteristics of patients with temporomandibular disorders: diagnostic and therapeutic implications. J Orofac Pain 1993; 7: 337-44.

[12] Wade JB, Price DD. Nonpathological factors in chronic pain: implications for assessment and treatment. In: Gatchel RJ, Weisberg JN, Eds. Personality characteristics of patients with pain. Washington DC: American Psychological Association 2000; pp. 89-107.

[13] Southwell J, Deary IJ, Geissler P. Personality and anxiety in temporomandibular joint syndrome patients. J Oral Rehabil 1990; 17: 239-43.

[14] BenDebba M, Torgerson WS, Donlin ML. Personality traits, pain duration and severity, functional impairment, and psychological distress in patients with persistent low back pain. Pain 1997; 72: $115-25$. 
[15] Wade JB, Dougherty LM, Hart RP, Cook DB. Patterns of normal personality structure among chronic pain patients. Pain 1992; 48: $37-43$.

[16] Booth-Kewley S, Vickers RR Jr. Association between major domains of personality and health behavior. J Person 1994; 62: 281-98.

[17] Ingledew DK, Brunning S. Personality, preventive health behaviour and comparative optimism about health problems. J Health Psychol 1999; 4: 193-208.

[18] Marshall GN, Wortmann CB, Vickers RJ Jr, Kusulas JW, Hervig LK. The Five-Factor Model of personality as a framework for personality-health research. J Person Soc Psychol 1994; 67: 27886.

[19] Carlson CR, Reid KI, Curran SL, et al. Psychological and physiological parameters of masticatory muscle pain. Pain 1998; 76: 279-307.

[20] Kight M, Gatchel RJ, Wesley L. Temporomandibular disorders: evidence for significant overlap with psychopathology. Health Psychol 1999; 18: 177-82.

[21] Ohrbach R, Dworkin SF. Five-year outcomes in TMD: relationship of changes in pain to changes in physical and psychological variables. Pain 1998; 74: 315-26.

[22] Rammelsberg P, LeResche L, Dworkin S, Mancl L. Longitudinal outcome of temporomandibular disorders: a 5-year epidemiologic study of muscle disorders defined by Research Diagnostic Criteria for Temporomandibular Disorders. J Orofac Pain 2003; 17: 9-20.

[23] Wright AR, Gatchel RJ, Wildenstein L, Riggs R, Buschang P, Ellis E III. Biopsychosocial differences between high-risk and low-risk patients with acute TMD-related pain. J Am Dent Assoc 2004; 135: 474-83.

[24] Gatchel RJ, Stowell AW, Wildenstein L, Riggs R, Ellis E III. Efficacy of an early intervention for patients with acute temporomandibular disorder-related pain. J Am Dent Assoc 2006; 137: 339-47.

[25] Sipilä K, Zitting P, Siira P, Niinimaa A, Raustia AM. Generalized pain and pain sensitivity in community subjects with facial pain: a case-control study. J Orofac Pain 2005; 19: 127-32.

[26] Vassend O, Krogstad BS, Dahl BL. Negative affectivity, somatic complaints, and symptoms of temporomandibular disorders. J Psychosom Res 1995; 39: 889-99.

[27] Krogstad BS, Jokstad A, Dahl BL, Vassend O. Relationships between risk factors and treatment outcome in a group of patients with temporomandibular disorders. J Orofac Pain 1996; 10: 48-53.

[28] Brown KW, Moskowitz DS. Does unhappiness make you sick? The role of affect and neuroticism in the experience of common physical symptoms. J Person Soc Psychol 1997; 72: 907-17.

[29] Feldman PJ, Cohen S, Doyle WJ, Skoner DP, Gwlatney JM. The impact of personality on the reporting of unfounded symptoms and illness. J Person Soc Psychol 1999; 77: 370-8.

[30] Crowne DP, Marlowe D. A new scale of social desirability independent of psychopathology. J Consult Psychol 1960; 24: 34954.

[31] Jamner LD, Schwartz GE. Self-deception predicts self-report and endurance of pain. Psychosom Med 1986; 48: 211-23.

[32] Deshields TL, Tait RC, Gfeller JD, Chibnall JT. Relationship between social desirability and self-report in chronic pain patients. Clin J Pain 1995; 11: 189-93.

[33] Salovey P, Sieber WJ, Smith AF, Turk DC, Jobe JB, Willis GB. Reporting chronic pain episodes on health surveys. National Center for Health Statistics, Vital Health Statistics 1992; 6.

[34] Mohn HC. Personality traits, subjective health complaints, experimental pain sensitivity, and psychophysiological responding in female temporomandibular disorder (TMD) patients. Oslo: University of Oslo 2008.

[35] Mohn C, Vassend O, Knardahl S. Experimental pain sensitivity in women with temporomandibular disorders and pain-free controls: the relationship to orofacial muscular contraction and cardiovascular responses. Clin J Pain 2008; 24: 343-52.

[36] Martinsen Ø, Nordvik H, Østbø LE. NEO-PI-R. Oslo: Gyldendal; 2003.
[37] Rudmin F. Norwegian short form of the Marlowe-Crowne Social Desirability Scale. Scand J Psychol 1999; 40: 229-33.

[38] Derogatis LR. SCL-90-R. Administration, scoring and procedures manual. Baltimore: Clinical Psychometric Research Inc 1983.

[39] Vassend O, Skrondal A. Interpretation of the SCL-90-R. A psychometric study based on a Norwegian national sample. Oslo: Institute of Aviation Medicine 2003.

[40] Steingrimsdottir OA, Vøllestad NK, Røe C, Knardahl S. Variation in reporting of pain and other subjective health complaints in a working population and limitations of single sample measurement. Pain 2004; 110: 130-9.

[41] Phillips J, Gatchel RJ. Extraversion-introversion and chronic pain. In: Gatchel RJ, Weisberg JN, Eds. Personality characteristics of patients with pain. Washington DC: American Psychological Association 2000; pp. 181-202.

[42] Miller TR. The psychotherapeutic utility of the Five-Factor Model of personality: a clinician's experience. J Person Assess 1991; 57: 415-33.

[43] Turk DC, Rudy TE, Kubinski JA, Zaki HS, Greco CM. Dysfunctional patients with temporomandibular disorders: evaluating the efficacy of a tailored treatment protocol. J Consult Clin Psychol 1996; 64: 139-46.

[44] Sipilä K, Veijola J, Jokelainen $\mathrm{J}$ et al. Association between symptoms of temporomandibular disorders and depression: an epidemiological study of the Northern Finland 1966 birth cohort. J Craniomandib Pract 2001; 19: 183-7.

[45] von Korff M, LeResche L, Dworkin, SF. First onset of common pain symptoms: a prospective study of depression as a risk factor. Pain 1993; 55: 251-8.

[46] Dersh J, Polatin PB, Gatchel RJ. Chronic pain and psychopathology:research findings and theoretical considerations. Psychosom Med 2000; 64: 773-86.

[47] von Korff M, Simon G. The relationship between pain and depression. Brit J Psychiatry 1996;168: 101-08.

[48] Bacon NMK, Bacon SF, Atkinson JH et al. Somatization symptoms in chronic low back pain patients. Psychosom Med 1994; 56: 118-27.

[49] McBeth J, Macfarlane GJ, Benjamin S, Silman AJ. Features of somatization predict the onset of chronic widespread pain. Arthritis Rheum 2001; 44: 940-6.

[50] Hedenberg-Magnusson B, Ernberg M, Kopp S. Presence of orofacial pain and temporomandibular disorder in fibromyalgia. Swed Dent J 1999; 23: 185-92.

[51] Dao TTT, Reynolds WJ, Tenenbaum HC. Comorbidity between myofascial pain of the masticatory muscles and fibromyalgia. J Orofac Pain 1997; 11: 232-41.

[52] Plesh O, Wolfe F, Lane N. The relationship between fibromyalgia and temporomandibular disorders: prevalence and symptom severity. J Rheumatol 1996; 23: 1948-52.

[53] International Headache Society. The international classification of headache disorders. Cephalalgia 2004; 24 (Suppl): 1-160.

[54] Bendtsen L. Central sensitization in tension-type headache possible pathophysiological mechanisms. Cephalalgia 2000; 20: 486-508.

[55] Wolfe F, Smythe HA, Yunus MB et al. The American College of Rheumathology 1990 criteria for classification of fibromyalgia: report of the Multicenter Criteria Committee. Arthritis Rheum 1990; 33: 301-55.

[56] McCreary CP, Clark GT, Merril RL, Flack V, Oakley ME. Psychological distress and diagnostic subgroups of temporomandibular disorder patients. Pain 1991; 44: 29-34.

[57] Michelotti A, Martina R, Russo M, Romeo R. Personality characteristics of temporomandibular disorder patients using MMPI. J Craniomandib Pract 1998; 16: 119-25.

[58] Huang GJ, LeResche L, Critchlow CW, Martin MD, Drangsholt MT. Risk factors for diagnostic subgroups of painful temporomandibular disorders (TMD). J Dent Res 2002; 81: 284-8.

[59] Rantala MAI, Ahlberg J, Suvinen TI, Savolainen A, Könönen M. Chronic myofascial pain, disk displacement with reduction and psychosocial factors in Finnish non-patients. Acta Odont Scand 2004; 62: 293-7. 
[60] LeResche L. Epidemiology of temporomandibular disorders: implications for the investigation of etiological factors. Crit Rev Oral Biol Med 1997; 8: 291-305.
[61] Dao TTT, LeResche L. Gender differences and pain. J Orofac Pain 2002; 14: 169-84.

(C) Mohn et al.; Licensee Bentham Open.

This is an open access article licensed under the terms of the Creative Commons Attribution Non-Commercial License (http://creativecommons.org/licenses/by-nc/3.0/) which permits unrestricted, non-commercial use, distribution and reproduction in any medium, provided the work is properly cited. 